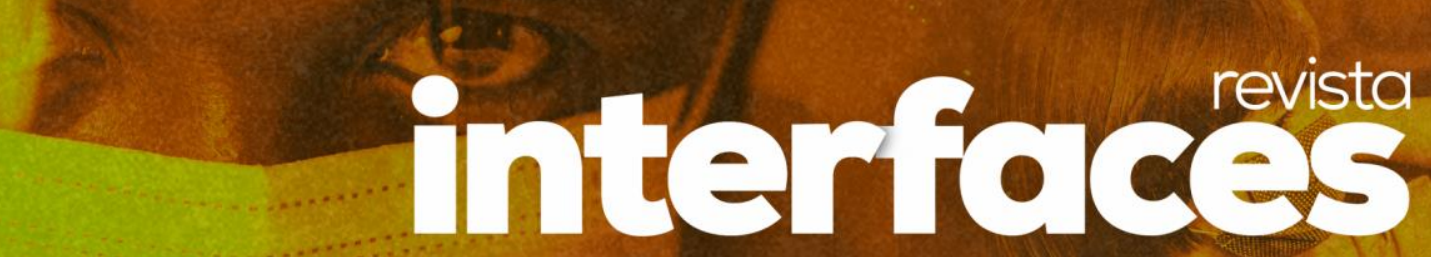

\title{
COVID-19 E CORRIDA VACINAL: POR QUE A PRESSA?
}

\author{
COVID-19 AND VACINAL RACING: WHY THE RUSH?
}

DOI: http://dx.doi.org/10.16891/2317-434X.v8.e3.a2020.pp603-604a

Willyenne Marília Dantasa, Deyvson Jonatan Rufino da Rochab

Programa de Pós-graduação em Desenvolvimento e Inovação Tecnológica em Medicamentos, Universidade Federal Rural de Pernambucoa Centro Universitário Estácio do Recife ${ }^{b}$ *E-mail: dantaswillyenne@gmail.com

Detectada pela primeira vez em novembro de 2019 em Wuhan (China) como uma pneumonia de causas desconhecidas, a COVID-19 se espalhou pelo mundo chegando ao Brasil oficialmente em 26 de fevereiro de 2020. A doença causada pelo vírus SARS-CoV-2 pode ocasionar desde sintomas leves como tosse, febre e cansaço a síndromes respiratórias graves. Em 11 de março de 2020, a OMS caracterizou a COVID-19 como pandemia. Atualmente, no mundo, quase 44 milhões de casos foram confirmados e mais de 1 milhão de mortes superando números de outros vírus como Influenza e HIV. Ainda não existe medicamento ou vacina específica para o SARS-CoV-2 e o tratamento baseia-se na sintomatologia do paciente, além de medidas para controle de transmissão como se trata de um vírus que acomete principalmente o sistema respiratório.

Algumas terapias são utilizadas no dia-a-dia após o diagnóstico da doença. A mais comum é a utilização de medicamentos de classes específicas, como alguns antiinflamatórios não-esteroidais, para controle da dor e febre; antibióticos, para a presença de possíveis infecções bacterianas; anticoagulantes para controle de tromboses que podem ser geradas pela resposta inflamatória; e corticoides que também podem atuar suprimindo a cascata inflamatória e auxiliar no tratamento de pacientes que utilizam a oxigenoterapia. A utilização de soro de pacientes que já foram acometidos pela COVID-19 e produziram anticorpos também é uma opção terapêutica, mas é caro e com baixa adesão. A melhor estratégia terapêutica, seguindo parâmetros como baixo custo, boa adesão da população e eficácia, seria a vacinação.

No estado pandêmico atual causado pela COVID19, o mundo se divide entre as opções de vacinas que estão em aprovação ou em fase final de testes, e algumas ainda na fase de estudos in vitro e in vivo. O tempo médio necessário para aprovação de uma vacina eficaz é de 20 anos desde os ensaios pré-clínicos e clínicos até a liberação comercial. O período de patenteamento é essencial para preservar o direito da instituição de pesquisa à exclusividade de sua invenção, podendo assim, ter o retorno com seu tempo de investimento e custos que foram direcionados aos estudos.

Desde 30 de janeiro de 2020, a OMS declarou a doença causada pelo novo coronavírus como Emergência de Saúde Pública Internacional e desde então incentiva países a tomar medidas preventivas assim como a comunidade científica internacional para estudo de novas estratégias para combate ao SARS-CoV-2. A corrida vacinal, derivada de um esforço mundial, caracteriza-se como uma resposta ao chamado e também à análise da situação pandêmica através dos números crescentes a cada dia.

Porém para que a liberação dessa vacina seja aprovada é necessário a quebra de alguns protocolos que incluem alguns parâmetros observados a longo prazo levando em consideração a necessidade de intervenção contra a COVID-19. O avanço das técnicas utilizadas no estudo e produção de vacinas também influenciam na velocidade dessa liberação, uma vez que em comparação com outras vacinas já liberadas há décadas, o tempo de produção foi bastante reduzido. $\mathrm{O}$ olhar da comunidade internacional para um problema de saúde preocupante é um aspecto a considerar na rapidez do desenvolvimento da vacina contra o SARS-CoV-2. Por fim, o auxílio governamental também é de suma importância no direcionamento de verbas para pesquisa, flexibilização de leis para aprovação rápida de vacinas e de sua distribuição e o amparo à população em momentos críticos.

A pressa na liberação da vacina contra a COVID19, com base em todos as considerações mencionadas deve-se à busca incentivada por um tratamento eficaz pelos órgãos competentes e a sensibilidade da população 
frente ao quadro pandêmico, já que atualmente temos uma

desenvolvimento de uma vacina.

forte base tecnológica e melhores ferramentas para o

\section{REFERÊNCIAS}

DE MELO, Cristiane Moutinho Lagos; SILVA, Guilherme A.S.; MELO, Alanne R.S.; DE FREITAS, Antônio Carlos. COVID-19 pandemic outbreak: The Brazilian reality from the first case to the collapse of health services. Anais da Academia Brasileira de Ciências, vol. 92, no. 4, p. 1-14, 2020. https://doi.org/10.1590/00013765202020200709 .
WHO, World Health Organization. Coronavirus disease (COVID-19) pandemic. Available https://www.who.int/emergencies/diseases/novelcoronavirus-2019 Acessed in: 28 sep 2020. 


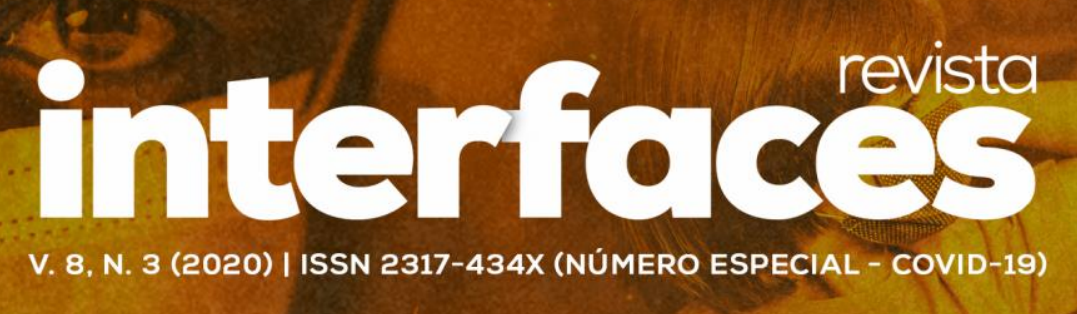

